\title{
Limited Urethral Mobilization Technique in Distal Hypospadias Repair with Satisfactory Results
}

\author{
Levent Elemen, Melih Tugay \\ Department of Pediatric Surgery, Faculty of Medicine, Kocaeli University, Kocaeli, Turkey
}

\begin{abstract}
Objective: To assess the outcomes of the Limited Urethral Mobilization (LUM) technique in distal hypospadias repair.

Material and Methods: Forty-seven patients, who were operated on with the LUM technique iduring a 6 years period, were grouped according to their ages. Age distribution in Group $1(n=37)$ and Group $2(n=10)$ were 6-36 and 37-72 months. Meatal localization was glanular in 31 , coronal in 7 and sub-coronal in 9 patients. Nine patients were secondary cases. The urethra proximal to the meatus was mobilized for a distance sufficient to allow it to reach the glans tip without tension. Then, the urethra was placed in the glanular bed and glanular reconstruction was performed. Operation duration, distance between the urethral meatus and the glans tip; and urethral mobilization length were measured and post-operative complications were noted.
\end{abstract}

Results: Operation durations were similar in both groups. Three-fold urethral mobilization was sufficient for construction of tension-free urethra-glanular anastomosis. No fistula or retraction of the urethral meatus and chordee were observed. One patient required meatotomy.

Conclusion: Distal hypospadias repair with the LUM technique is simple and effective. As no new urethral tube is constructed there is no risk of fistula. A slit-like urethral meatus with good functional results was obtained with the use of theLUM technique.

Key Words: Hypospadias, limited urethral mobilization

Received: 22.11.2010 Accepted: 07.02.2011

\section{Introduction}

Hypospadias is defined as an abortive development of the urethral spongiosum and ventral prepuce along with an arrest in the normal embryological correction of penile curvature (1). It is one of the most common congenital anomalies, which occurs in approximately 1 of 200 to 1 of 300 live births $(1,2)$. The majority of cases are distal hypospadias with an incidence of $75 \%$ (2). The main goals in hypospadias surgery are penile straightening, urethroplasty, meatoplasty and glanduloplasty, scrotoplasty, and skin coverage (1). The success of the operation is determined by excellent cosmetic appearance and normal voiding in a straight forward direction from the tip of the glans $(1,2)$. Various surgical techniques were developed to achieve these objectives (3). The fact that more than 300 different operations are described in the literature reflects the wide spectrum of the anomaly, and proves that the treatment has not been perfected $(1,3)$.

Any technique to repair distal hypospadias should be simple, easy and applicable with good cosmetic and functional results. Herein, we report 47 patients with distal hypospadias who were operated on using the Limited Urethral Mobilization (LUM) technique.

\section{Materials and Methods}

Between January 2004 and January 2010, the LUM technique was used in 47 patients for correction of distal hypospadias. The patients with glanular $(n=31)$, coronal $(n=7)$ and sub-coronal $(n=9)$ hypospadias were included in the study. Six patients had minimal chordee and 2 patients had glans tilt related to shortage of ventral skin. Three patients had already undergone MAGPI (meatal advancement glanuloplasty), and 6 patients TIPU (tubularized incised plate urethroplasty) repairs and subsequent circumcisions with unsuccessful results. Two of these secondary cases had sub-coronal and 7 had glanular meatus prior to our operation. Age distribution of the patients was 6 months to 6 years. The patients were classified into two groups according to their ages. Group 1 included 37 patients within an age range of 6 to 36 months and Group 2 included 10 patients within an age range of 37 to 72 months.

All the operations were carried out under general anesthesia and performed by two pediatric surgeons who were experienced in hypospadias surgery. At the beginning of the operation, incision lines were outlined and marked (Figure 1). A tourniquet was employed. The artificial erection test was performed, and in the case of existence of a chordee, the pe- 
nile skin was degloved and the dysplastic tissue was removed. A suitable-sized, non-toxic PVC catheter (Feeding tube, Bıçakçılar Tıbbi Cihazlar San. ve Tic. AŞ, Turkey) was placed in the urethra. The distance between the urethral meatus and the glans tip was measured and recorded (Figure 2). The meatus was circumscribed and the urethra proximal to the meatus was mobilized circumferentially for a distance sufficient to allow the urethra to reach the tip of the glans without tension. In the presence of a laterally diverging corpus spongiosum, we extended our circumferential dissection laterally in order to contain as much spongiousum as possible. Obviously, in some patients having all the spongiosum in the incision borders was not manageable, thus some was left attached to the corpora cavernosa. The length of the urethral mobilization was measured and recorded (Figure 3). If there was a thin and transparent urethra, we lengthened urethral mobilization as this portion would be excised after repositioning and securing the urethra in the glans wings. If the length of the thin portion exceeded 3-4 $\mathrm{mm}$, we switched the technique so as not to increase urethral mobilization length. The ventral glans was incised deeply into the corpora cavernosa and the glans wings were mobilized laterally. The glandular bed was prepared and then the mobilized urethra was placed in it (Figure 4). The dorsal lip of the urethra was sutured to the glans tip with four interrupted 6/0 polydioxanone sutures (PDS II, Ethicon, UK).

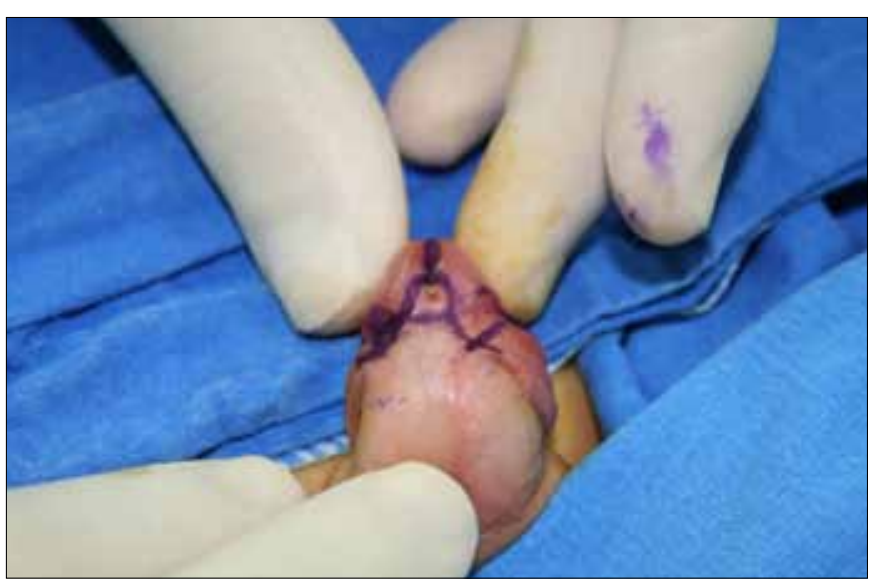

Figure 1. Incision lines outlined and marked

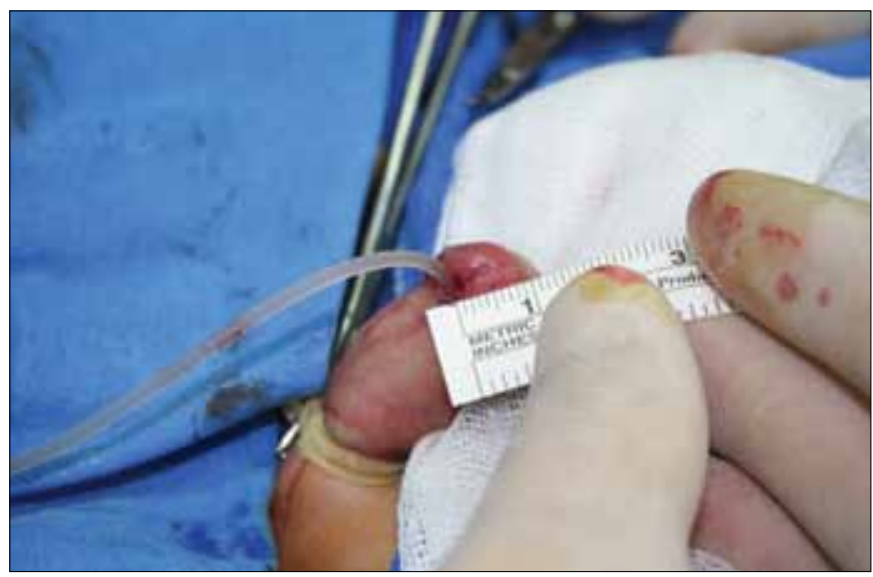

Figure 2. The distance between the urethral meatus and tip of the glans measured and recorded
Glans wings were wrapped around the urethra as in the normal configuration, and sutured with 2 layers of interrupted sub-epithelial $6 / 0$ polydioxanone sutures. The deeper layer secured the urethra to the glanular tissue and the superficial layer approximated the glans wings. The anterior lip of the urethra was secured to the glans with four interrupted sutures, two on each side of the midline. The penile tourniquet, which was used intermittently during dissection, was removed when the glans reconstruction was completed. Circumcision was performed in all primary cases and the operation was terminated (Figure 5). A compression dressing was applied.

An urethral catheter was left in place for at least 3 days. If the catheter dislodged after the post-operative $3^{\text {rd }}$ day and the patient was able to urinate, no catheter was re-inserted. Otherwise, a new urethral catheter was inserted and kept until the post-operative $5^{\text {th }}$ day. Usually, on the post-operative $5^{\text {th }}$ day the diversion was removed and the patient was discharged after voiding. All patients were given oxybutynin 0.2 $\mathrm{mg} / \mathrm{kg}$ daily in two doses to prevent bladder spasms, trimetoprim $6 \mathrm{mg} / \mathrm{kg}$ daily in two doses; and allobarbital $60 \mathrm{mg} / \mathrm{kg}$, adiphenine hydrochloride $50 \mathrm{mg} / \mathrm{kg}$ and paracetamol $30 \mathrm{mg} /$ $\mathrm{kg}$ daily in four doses as long as the bladder was catheterized.

On the post-operative $15^{\text {th }}$ day, urethral calibration was performed with 6-8 Fr catheters in children aged up to 3 years and with $10 \mathrm{Fr}$ catheters in older children. Patients were called

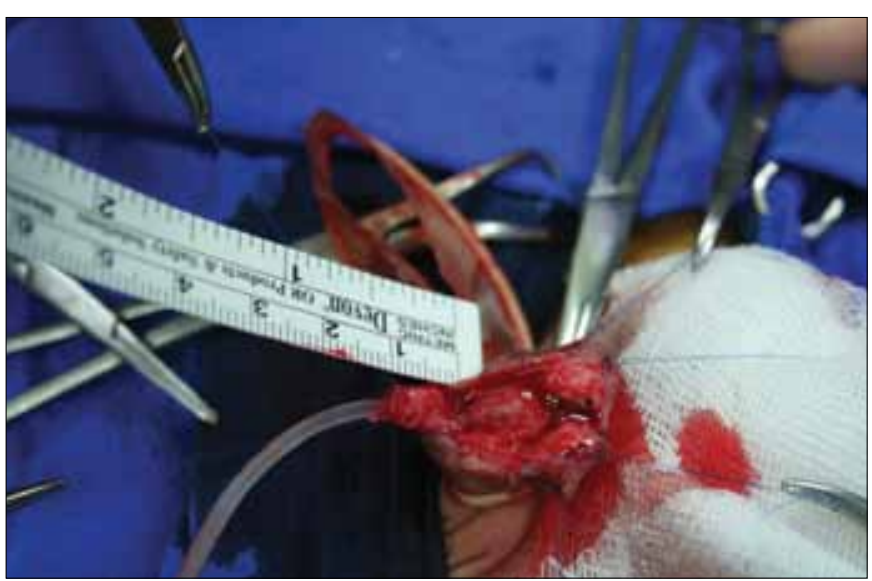

Figure 3. The length of urethral mobilization measured and recorded

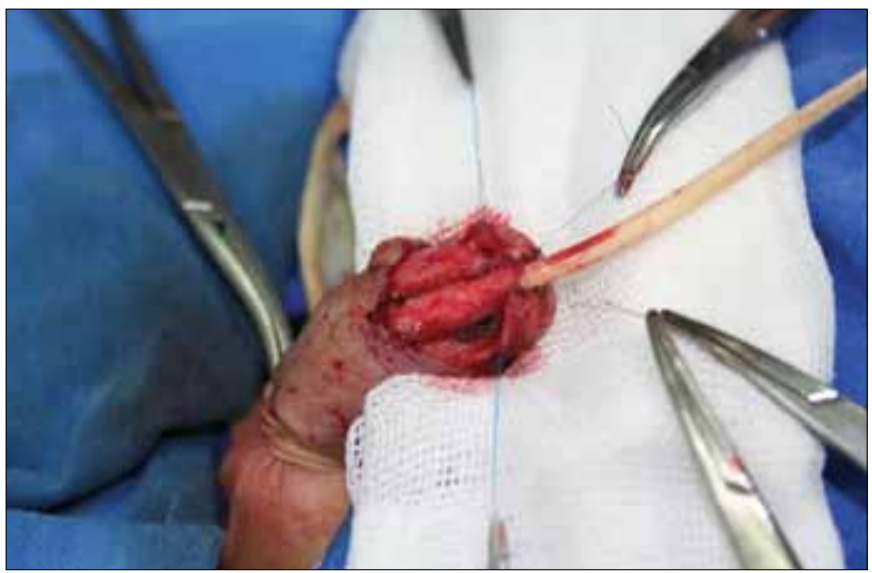

Figure 4. Glanular bed prepared and mobilized urethra placed in 
for office visits on the post-operative $6^{\text {th }}$ month to evaluate the cosmetic appearance (Figure 6) and functional results. Cosmesis was evaluated with a slit-like meatus at the tip of the glans and lack of chordee, while function was evaluated with a good stream of urine.

Statistical analyses were performed with SPSS 13.0 (Statistical Software Package for Social Sciences, SPSS Inc, Chicago, IL, USA) software system. The quantitative data was expressed as mean \pm standard deviation and the comparison of the data according to the groups was performed with Students t Test. The statistical significance was set at $p$ less than 0.05 with a confidence rate of $95 \%$.

\section{Results}

A consistent re-evaluation of the patients' medical records was possible by means of the electronic database of our hospital. There were no early complications such as bleeding, hematoma or infection.

The mean age of the patients was $32.76 \pm 23.65$ months. The mean age of the patients in Group 1 was $21.54 \pm 12.57$ months and in Group 2 was $54.50 \pm 14.05$ months $(p<0.05)$ (Table 1). One patient, who was operated on because of glanular hypospadias, was excluded from the study as he was older (15 years old) than the age range of the study groups.

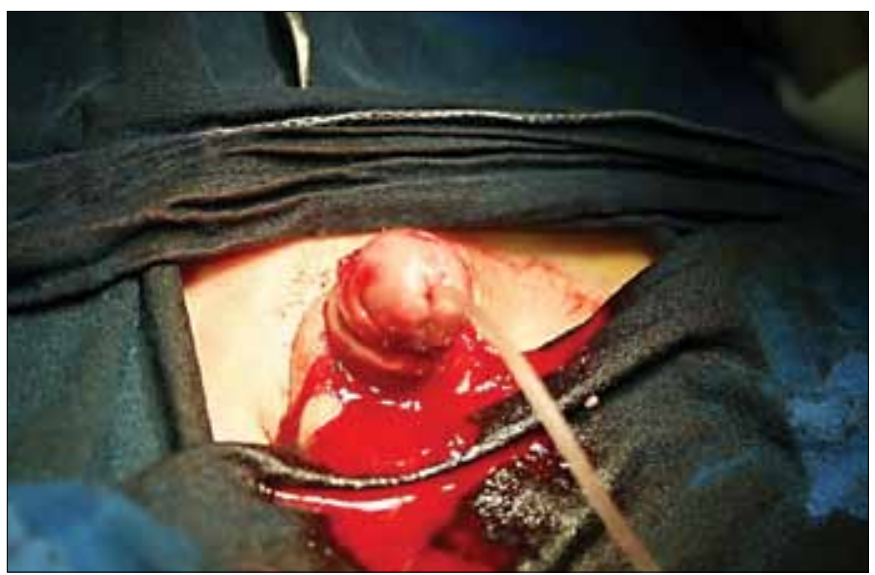

Figure 5. Operation terminated

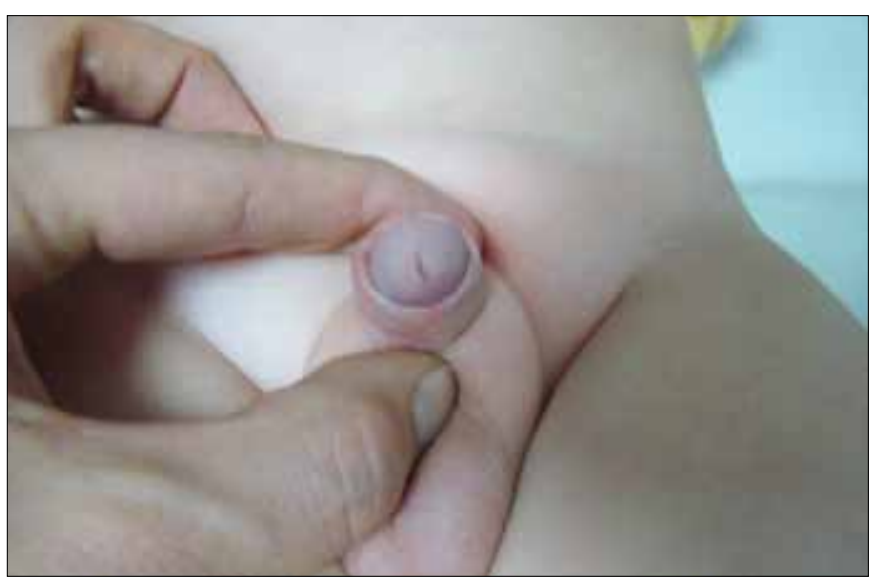

Figure 6. Post-operative $6^{\text {th }}$ month appearance with a good cosmetic result
The mean distance required for carrying the urethral meatus to the glans tip was $5.74 \pm 2.03 \mathrm{~mm}$ and the length of the mobilized urethra was $17.06 \pm 6.20 \mathrm{~mm}$. The ratio of the length of the mobilized urethra to the distance required for carrying the urethral meatus to the glans tip was $3.02 \pm 0.51$. When we considered these values according to age groups, we found that the distance required for carrying the urethral meatus to the glans tip in Group 1 was $5.43 \pm 2.03 \mathrm{~mm}$ and in Group 2 was $6.90 \pm 1.66 \mathrm{~mm}(p=0.031)$; and the length of mobilized urethra in Group 1 was $16.18 \pm 6.45 \mathrm{~mm}$ and in Group 2 was $20.30 \pm 3.86 \mathrm{~mm}(p=0.018)$ (Table 1). The ratios of the lengths of the mobilized urethras to the distances between the urethral meatus and the glans tip in Group 1 and Group 2 were $3.04 \pm 0.57$ vs. $2.97 \pm 0.17$ respectively $(p=0.56)$ (Table 1$)$.

The mean operation time was $58.82 \pm 22.87$ minutes. Comparison of operation times in Group 1 (60.94 22.32 minutes) and Group $2(51.00 \pm 24.35$ minutes) revealed that the two groups were comparable $(p=0.26)$ (Table 1$)$. Usually, the penile tourniquet time was limited to 15 minutes but on rare occasions, it was permitted to stay for twenty minutes.

The mean catheter stay period was $3.48 \pm 1.45$ days. The mean catheter stay periods in Group 1 (3.35 \pm 1.39 days) and in Group 2 (4.00 \pm 1.63 days) were similar $(p=0.27)$ (Table 1).

The mean follow-up period was $33.21 \pm 16.87$ months. The mean follow-up period in Group 1 (32.45 \pm 18.21 months) and

Table 1. The demographic features and statistical comparison of the study groups

\begin{tabular}{|c|c|c|c|}
\hline & $\begin{array}{c}\text { Group } 1 \\
(n=37)\end{array}$ & $\begin{array}{c}\text { Group } 2 \\
(n=10)\end{array}$ & $p$ \\
\hline $\begin{array}{l}\text { Age } \\
\text { (Mean } \pm S D) \\
\text { (months) }\end{array}$ & $21.54 \pm 12.57$ & $54.50 \pm 14.05$ & $<0.05^{\mu}$ \\
\hline $\begin{array}{l}\text { Gap* } \\
(\text { Mean } \pm S D) \\
(\mathrm{mm})\end{array}$ & $5.43 \pm 2.03$ & $6.90 \pm 1.66$ & $0.031^{\mu}$ \\
\hline $\begin{array}{l}\text { Urethral } \\
\text { mobilization length } \\
(\text { Mean } \pm \text { SD) } \\
(\mathrm{mm})\end{array}$ & $16.18 \pm 6.45$ & $20.30 \pm 3.86$ & $0.018^{\mu}$ \\
\hline $\begin{array}{l}\text { Gap / Urethral } \\
\text { mobilization length } \\
(\text { Mean } \pm \text { SD) }\end{array}$ & $3.04 \pm 0.57$ & $2.97 \pm 0.17$ & 0.56 \\
\hline $\begin{array}{l}\text { Operation time } \\
\text { (Mean } \pm \text { SD) } \\
\text { (minutes) }\end{array}$ & $60.94 \pm 22.32$ & $51.00 \pm 24.35$ & 0.26 \\
\hline $\begin{array}{l}\text { Catheter stay period } \\
\text { (Mean } \pm \text { SD) } \\
\text { (days) }\end{array}$ & $3.35 \pm 1.39$ & $4.00 \pm 1.63$ & 0.27 \\
\hline $\begin{array}{l}\text { Follow-up time } \\
\text { (Mean } \pm \text { SD) } \\
\text { (months) }\end{array}$ & $32.45 \pm 18.21$ & $36.00 \pm 10.83$ & 0.44 \\
\hline
\end{tabular}


in Group 2 (36.00 \pm 10.83 months) were comparable $(p=0.44)$ (Table 1).

Five patients were admitted with reduction in urinary flow calibration in the early post-operative period, and in 4 patients the problem was solved with gentle dilatations. One patient, who had already undergone an unsuccessful sub-coronal hypospadias repair required meatotomy. In one patient, the most distal of the glans approximation sutures disrupted leading to a minor detachment in the glans. Although, this condition was a handicap for cosmetic appearance no functional abnormality occurred. A slit-like meatus at the tip of the glans was obtained in 41 patients, while a round shape meatus was present in 6 patients. No urethra-cutaneous fistula, retraction of the urethral meatus or recurrent chordee were observed.

\section{Discussion}

Urethral advancement for hypospadias repair was first introduced in 1898 by Beck $(4,5)$. Utilization of this procedure was not consistently successful because of the high incidence of postoperative chordee due to inadequate mobilization of the urethra (5). After that time, numerous ingenious methods for urethral advancement were reported $(2,3,5-7)$. Koff et al., modified and favored the technique with satisfactory results (8). In 1999 Türken et al., reported successful results in patients who were operated on with limited urethral mobilization (LUM) and eccentric circummeatal-based skin flap technique. This technique was based on the mobilization of the urethra with an eccentric circummeatal-based skin flap and glanular reconstruction by repositioning of the mobilized urethra in the glanular bed $(2,7)$. Utilization of an eccentric circummeatalbased skin flap integrated to the LUM technique was a preventive measure to preserve the blood supply of the distal urethra $(2,7)$.

Our technique does not comprise skin flap use; and instead meticulous mobilization of the distal urethra is performed. It is known that there is a fine network between the urethral branch of the internal pudendal artery and terminal branches of the dorsal penile artery, which creates an important vasculature for the urethra (9). Thus, the fear of devascularization due to urethral mobilization seems to be unfounded (10). In the present series, 5 patients admitted with reduction in urinary flow calibration in the post-operative early period, and the problem was solved with only one gentle meatal dilatation in 4 patients. One patient, who had had a previous sub-coronal hypospadias surgery experienced meatal stricture and undergone meatotomy. However, as four patients did not require re-operation for meatal strictures, we believe that the condition might have been due to mild ischemia in the area at greatest risk. Evidently, the dual blood supply of the urethra prevented necrosis of the distal part, which would have caused a fibrotic stricture of the newly created meatus $(3,9)$. The meatal stricture seen in 1 patient might have been because of inadequate excision of the former fibrotic tissue and ongoing fibrosis. Therefore, we agree with Alkan et al., that true fibrotic strictures of the meatus do not occur following mobilization of the distal urethra (2). Besides, performance of $\mathrm{V}-\mathrm{Y}$ or $\Psi$ incisions of the glanular tissue, which were reported to decrease the post-operative stenosis rate, may be incorporated in the technique for obtaining a wider orifices $(11,12)$. Our stricture rate $(2.1 \%)$ seems to be comparable with previously reported similar series $(2,6,13)$.

Nine patients in our series had previously undergone unsuccessful surgery for hypospadias. Two of these patients had sub-coronal and 7 patients had glanular meatus prior to our operation. With the use of the LUM technique, it was possible to carry these meatus' to the tip of the glans. We believe that utilization of this technique in secondary reconstructions seems to be effective in achieving good cosmetic and functional results $(2,6,10,14)$.

Many different techniques are used to correct the distal hypospadias, especially in types confined to the glanular and coronal region. The MAGPI technique, which was favored for these cases, has sometimes difficulty in correction of the chordee $(15,16)$. As reported before, the LUM technique relieves glanular chordee by mobilizing the urethra into the glans (5-7). The technique of chordee correction by mobilization of the distal urethra is simple and effective. Also, unsatisfactory cosmesis with retraction of newly constructed urethral meatus related to MAGPI repair is resolved with the use of the LUM technique $(5,15,16)$.

In the present series, the mean mobilized length of the urethra was $17.06 \pm 6.20 \mathrm{~mm}$, and the distance necessary to carry the urethral meatus to the glans tip was $5.74 \pm 2.03 \mathrm{~mm}$. To have more precise results, we grouped our patients according to their ages. Although the mobilized length of the urethra $(16.18 \pm 6.45 \mathrm{~mm}$ vs. $20.30 \pm 3.86 \mathrm{~mm}, \mathrm{p}=0.018)$ and the distance necessary to carry the urethral meatus to the glans tip $(5.43 \pm 2.03 \mathrm{~mm}$ vs. $6.90 \pm 1.66 \mathrm{~mm}, \mathrm{p}=0.031)$ were significantly greater in older boys compared to the youngsters, their ratios remained the same (3.04 vs. $2.97, p=0.56)$. Thus, our data revealed that a ratio of 2.9 to $3: 1$ would be adequate to preclude chordee. Atala proposed that a 4 to $5: 1$ ratio should have been achieved between the mobilized length of the urethra and the initial distance from the meatus to the distal margin of the glanular groove to prevent chordee in urethral mobilization (5). Interestingly, the data from the present study reveal that a shorter mobilization length can also provide secure urethra-glanular anastomosis without chordee; and closely resembles the findings of Hammouda et al. (17), who found that a three fold urethral mobilization was sufficient.

Forty-one patients had a slit like meatus at the tip of the glans. The rest of the patients had round shape appearance of the meatus with acceptable cosmetic results. These patients were the early cases of our series. We believe that this condition was due to insufficiency in dissection during mobilization of the urethra and inadequate preparation of the glanular bed as described before $(2,3,5)$. After those mild results, we reviewed our technique to achieve longer mobilization, more widening of the glans and deeper dissection of the glanular groove.

The present study has two limitations due to certain technical aspects. Firstly, the use of the LUM technique in proximal hypospadias is questionable. The natural elasticity of the urethra is the main factor for using this technique and the continuing growth of the spongy urethra keeps pace with the general 
growth of the child $(3,5,10,14)$. The LUM repair in distal hypospadias offers a relatively risk-free opportunity to advance the urethral meatus to the glans tip without constructing a neourethra, thus reducing the risk of fistula formation $(6,10)$. On the other hand, release of chordee in proximal shaft hypospadias results in an increase in the distance between the urethral meatus and the glans, and the use of this procedure in greater distances may apparently result in secondary chordee and even penile shortening $(2,10)$. Thus, we can not comment on this situation as we did not use the technique for proximal hypospadias repair, but in such cases unsatisfactory results can be predicted (10).

The presence of a thin and transparent urethra proximal to the meatus is the second limitation of the LUM technique. The use of this procedure in these cases necessitates high skill and meticulous dissection in order not to injure the urethra (6). Besides, it is obvious that the thin portion of the urethra would necrose because of its poor vascularization. When a thin urethra was present, we extended the urethral mobilization length slightly more as we would excise this portion after repositioning and securing the urethra in the glans wings. If the length of the thin portion of the urethra exceeded 3-4 mm, especially in the sub-coronal hypospadias cases, we switched to another technique in order not to increase the urethral mobilization length.

In conclusion, although perhaps only useful in distal hypospadias repairs, the LUM technique seems to be a good method with satisfactory cosmetic and functional results. A 2.9 to 3 fold urethral mobilization length is adequate to prevent chordee and achieve tension-free urethra-glanular anastomosis.

\section{Conflict of Interest}

No conflict of interest was declared by the authors.

\section{References}

1. Baskin LS, Ebbers MB. Hypospadias: anatomy, etiology, and technique. J Pediatr Surg 2006;41:463-72. [CrossRef]

2. Alkan M, Oguzkurt P, Ezer SS, Ince E, Hicsonmez A. Evaluation of the results of eccentric circummeatal-based flap with combined limited urethral mobilization technique for distal hypospadias repair. J Pediatr Urol 2008;4:206-9. [CrossRef]

3. Hamdy $\mathrm{H}$, Awadhi MA, Rasromani KH. Urethral mobilization and meatal advancement: a surgical principle in hypospadias repair. Pediatr Surg Int 1999;15:240-2. [CrossRef]

4. Beck C. A new operation for balanic hypospadias. N Y Med J 1898;67:147.

5. Atala A. Urethral mobilization and advancement for midshaft to distal hypospadias. J Urol 2002;168:1738-41. [CrossRef]

6. Awad MM. Urethral advancement technique for repair of distal penile hypospadias: A revisit. Indian J Plast Surg 2006;39:34-8. [CrossRef]

7. Türken A, Senocak ME, Büyükpamukçu N, Hiçsönmez A. The use of eccentric circummeatal-based flap with combined limited urethral mobilization technique for distal hypospadias repair. Plast Reconstr Surg 1999;103:525-30. [CrossRef]

8. Koff SA, Brinkman J, Ulrich J, Deighton D. Extensive mobilization of the urethral plate and urethra for repair of hypospadias: the modified Barcat technique. J Urol 1994;151:466-9.

9. McGowan AJ Jr, Waterhouse K. Mobilization of the anterior urethra. Bull NY Acad Med 1964;40:776-82.

10. Haberlik A, Schmidt B, Uray E, Mayr J. Hypospadias repair using a modification of Beck's operation: followup. J Urol 1997;157: 2308-11. [CrossRef]

11. Adorisio O, Elia A, Landi L, Taverna M, Malvasio V, D'Asta F, Alfredo Danti $D$. The importance of patient selection in the treatment of distal hypospadias using modified Koff procedure. J Pediatr Urol 2010;6:139-42. [CrossRef]

12. Roodsari SS, Mulaeian M, Hiradfar M. Urethral advancement and glanuloplasty with $\mathrm{V}$ flap of the glans in the repair of anterior hypospadias. Asian J Surg 2006;29:180-4. [CrossRef]

13. Holland AJ, Smith GH, Cass DT. Clinical review of the 'Snodgrass' hypospadias repair. Aust N Z J Surg 2000;70:597-600. [CrossRef]

14. Karamürsel S, Celebioğlu S. Urethral advancement for recurrent distal hypospadias fistula treatment. Ann Plast Surg 2006;56:423-6. [CrossRef]

15. Duckett JW, Snyder HM 3rd. The MAGPI hypospadias repair in 1111 patients. Ann Surg 1991;213:620-5. [CrossRef]

16. Hastie KJ, Deshpande SS, Moisey CU. Long-term follow-up of the MAGPI operations for distal hypospadias. Br J Urol 1989;63: 320-2. [CrossRef]

17. Hammouda HM, Hassan YS, Abdelateef AM, Elgammal MA. New concept in urethral advancement for anterior hypospadias. J Pediatr Urol 2008;4:286-9. [CrossRef] 